\title{
Research on the Research-Teaching Model Application Based on Analysis of Differential
}

\author{
Shufeng Wang1, Di Tian² \\ Accounting Institute, Heilongjiang Bayi Agricultural University, Daqing, China \\ School of Management, Changchun University, Changchun, China \\ Email: wsf630817@163.com
}

How to cite this paper: Wang, S.F. and Tian, D. (2018) Research on the Research-Teaching Model Application Based on Analysis of Differential. Open Access Library Journal, 5: e4095.

https://doi.org/10.4236/oalib.1104095

Received: October 30, 2017

Accepted: January 22, 2018

Published: January 25, 2018

Copyright () 2018 by authors and Open Access Library Inc.

This work is licensed under the Creative

Commons Attribution International

License (CC BY 4.0).

http://creativecommons.org/licenses/by/4.0/

c) (i) Open Access

\begin{abstract}
In view of the objective reality that many colleges and universities confused Research-Education Training Mode with Research Teaching Method Pattern in the course of transformation of college-running orientation, combined with many years of experience in first-line college teaching, this paper expounded the specific background of research-teaching, systematically analyzed the important differences between research education, research teaching and traditional teaching, and explored the application principles and requirements of the training mode of research teaching.
\end{abstract}

\section{Subject Areas}

Education

\section{Keywords}

Difference Analysis, Research-Oriented Teaching, Education Training Model

\section{1. 引言}

近年来, 国内高校掀起了办学类型的 “转型热”, 一些以实践教学为主的 “教 学型” 大学, 比如黑龙江八一农垦大学、江西师范大学等, 纷纷将办学定位转 向 “教学研究型” 大学, 还有一些如山西大学、浙江工业大学等的办学类型定 位由教学研究型大学转向 “研究型” 大学, 这体现了国内高校的教育培养模 式进步。但实践表明, 很多高校在明确提出转型后, 在教学、科研、教务、师 资、学生等管理层面仍然 “穿新鞋走老路” ，并未按照新的教育培养模式规律 要求进行相适宜的改革, 有的高校误将 “研究性教学方法” 作为建设教学研究 型或研究型大学的 “名片” , 甚至有些普通高校对研究性教学方法应用都搞不 清楚, 胡乱编造文件要求教师执行, 严重阻碍了新型大学的建设进程。这主 
要是因为各高校决策机构和领导对适应研究类型大学的教育培养模式和主流 教学方法差异认识不清, 从而造成不能按照创新教学模式客观规律要求办学。

\section{2. 研究型大学发展背景}

每一种教学模式都服务于特定类型的学校建设目标。通常, 大学有三种 类型：一是专注于为社会实践单位培养应用操作型人才的教学型或应用型大 学, 主要包括职业技术院校和二表招生的普通本科院校; 二是培养社会实践 应用与科研创新能力人才并重的教学研究型或应用研究型大学, 主要是一表 招生院校和少量二表院校; 三是注重培养科技创新人才为主并在科研学术特 别是以前沿科学和尖端科学领域著称有特色建树的研究型大学, 主要是重点 院校和部分高考 “0 批次” 和 “第一批次” 招生的知名品牌高校。由于第二 种类型并不具有完全均衡性, 实践中或偏重于教学型或偏重于研究型, 所以 可将国内大学总体划分为两类: 教学型或偏重于教学型大学(可统称为 “教学 型大学” 或 “应用型大学” ), 研究型或偏重研究型大学(统称为 “研究型大 学” )。根据新东方高考网站发布的艾瑞深中国校友会网 2018 中国大学排 行榜 700 强进行整理,得出全国 700 所高校办学类型状况, 如表 1 所示。

Table 1. The division of the type of campus in China's public universities 表 1. 中国公办大学办学类型划分

\begin{tabular}{|c|c|c|c|c|}
\hline & 办学类型定位 & 数量 & 占比 & 备注 \\
\hline \multirow{5}{*}{$\begin{array}{l}\text { 研 } \\
\text { 究 } \\
\text { 型 } \\
\text { 大 } \\
\text { 学 }\end{array}$} & 中国研究型 & 37 & $5.29 \%$ & $\begin{array}{l}\text { 北大、清华、中国人大均八星级, 浙大、复旦、 } \\
\text { 上海交大、武大、南大、中山、吉大、华中科技、 } \\
\text { 川大、天大、南开、西安交大、中科技、哈工大 } \\
\text { 等 } 15 \text { 所均 } 7 \text { 星级的世界知名高水平中国顶尖大 } \\
\text { 学, 其余为六星级世界高水平或世界知名的中国 } \\
\text { 一流或顶尖大学。 }\end{array}$ \\
\hline & 行业特色研究型 & 40 & $5.71 \%$ & $\begin{array}{l}\text { 中国农大排名前 } 30 \text {, 电子科大、中国地质等均 } \\
\text { 列百强内。 }\end{array}$ \\
\hline & 特色研究型 & 15 & $2.14 \%$ & $\begin{array}{l}\text { 全国百强名校 } 39 \text { 名, 101 200 名之间 } 15 \text { 所, 均 } \\
\text { 为世界知名中国顶尖或一流大学, 如中国农大、 } \\
\text { 北京协和、北京中医药大学、北交大、上海财经、 } \\
\text { 东北林大、暨南大学、华北电力、东北财大、江 } \\
\text { 南大学等。 }\end{array}$ \\
\hline & 区域研究型 & 38 & $5.43 \%$ & $\begin{array}{l}\text { 排名含百强内的上海大学、苏州大学、长安大学 } \\
\text { 暨南大学、云南大学、深圳大学、福州大学、广 } \\
\text { 西大学、燕山大学等。其余都在 } 300 \text { 名内如河北、 } \\
\text { 安徽、辽宁、新疆、西藏等地方大学。 }\end{array}$ \\
\hline & 区域特色研究型 & 152 & $21.71 \%$ & $\begin{array}{l}\text { 全国百强内的湖南师范、华南师范、首都师范、 } \\
\text { 福建师范、华南农大、浙江师范、杭州电子科技、 } \\
\text { 上海理工、天津师范、首都医科大等 } 10 \text { 所, 东 } \\
\text { 北石油大学等多在 } 101 \text { 400 间。 }\end{array}$ \\
\hline \multirow[t]{2}{*}{$\begin{array}{l}\text { 教 } \\
\text { 学 } \\
\text { 型 }\end{array}$} & 应用型 & 418 & $59.71 \%$ & $\begin{array}{l}200 \text { 名开外如湖北工大、上海外贸、山西财经、 } \\
\text { 安徽财大、哈商大等 } 26 \text { 所, } 300 \text { 名外的 } 88 \text { 所如 } \\
\text { 西安石油大学、长春大学、佳木斯大学、黑龙江 } \\
\text { 八一农垦大学等, 余 } 304 \text { 所均排在 } 401 \text { 后, }\end{array}$ \\
\hline & 合计 & 700 & $100 \%$ & 不含独立学院和民办高校 \\
\hline
\end{tabular}


表中看出, 中国高校仍以教学型或应用型大学为主, 700 所公办高校有 近 60\%位完全的教学或应用型, 各类研究型大学合计略超过 $40 \%$, 如果剔除 一些教学研究型或研究教学型中科研、学术和学科特色优势不明显或偏重于 应用教学的大学, 即按照毕业生辐射区域、校友杰出、科研领先和办学特 色等四大核心标准对区域研究型和区域特色研究型进行综合实力打分 不超过 61 分高校纳入教学或应用型, 全国应有 $20 \%$ 25\%的高校属于教 学研究型或研究教学型研究型教育定位。也就是说, 全国普通高校向研 究型大学转型的比重或空间将占高校总量近四分之一。从发展角度讲, 每一种 大学都应沿着 “教学型 $\rightarrow$ 教学研究型 $\rightarrow$ 研究型” 的运行脉络递进发展, 每一 次转型和跨越, 都是高校办学水平、综合实力进步的检阅, 也必然带来管理 体制和教学模式的转变。不同类型大学孕育着不同的教育培养模式, 也须有 与之相适应的教学管理体制和创新教学方法或模式。

\section{3. 研究型教育与研究性教学的差异比较}

当研究型教育培养模式确立后, 研究型大学便认识到 “填鸭式” 的传统 教授型教学方法只能实现知识传导和技能操作而无法激发学生的创新思想和 科研能力, 难于将占居高校主导地位的大学生引入到科研学术中来, 发挥其 在高校科研阵营中的战斗力。为此, 需实施一种能够以学生为课堂主体、全 面引导和激发学生科研能量为主导从而充分调动学生科研主观能动性的创新 教学方法, 于是 “研究性教学方法” 便应运而生。

\section{1. 研究型教育模式与研究性教学方法的差异分析}

\subsection{1. 涵义不同}

研究型教育模式是以科研学术和教研为主导功能, 突出研究生培养和学 科建设, 同时兼顾本科教学和专业建设并强化研究性教学方法应用的或教育 培养模式。而研究性教学则是以普及专业基础知识教育和推广前沿技术理论 思想为依托, 以培养学生研究、创造能力和创新性思维为指导思想, 激发学 生主动发现问题和独立解决问题为宗旨, 并努力将教师科研思想和成果传导 给学生的教学方法[1]。可见, 研究型教育是学校的办学定位, 研究性教学方 法是教师采用的以学生为课堂主体、以教师为主导的教学模式, 因此又称 “研 究性教学模式”。

\subsection{2. 性质不同}

研究型教育模式是为 “研究型大学” 孕育的一种新型人才培养模式, 是 支撑研究型大学建设运行的重要内驱力, 也是引领高校发展的核心竞争力标 志。它是集学生培养方案和教学计划制订、课程结构调整、课程质量建设、 教学资源配置、教材建设、教学方法等多更新等于一体的教育培养体系, 体 现了研究型大学同教学型大学在建设体系、教学模式等方面既相辅相承、又 对立统一的关系, 反映了高校发展进步和建设目标转型对新型教育教学方法 和服务模式的客观需求。而研究性教学则是研究性教学模式中的一种教学方 法, 是由传统教学模式下 “局部探究法” 和 “专题研究法” 逐步发展演进而 
来的创新教学方法 [2]。随着职业型和学术型高校类型改革的逐步深入, 学术 型院校成为专门培养科研学术型人才的主阵营, 新的使命决定了研究性教学 方法应成为研究型大学建设的一种以传授专业知识与科研思想、知识与方法 相结合的崭新教学方法, 体现了新型大学发展目标对创新教学方法的客观要 求。

综上, 研究型教育是以突出科研建设为核心的教育培养模式, 牵涉到高 校从上到下方方面面的重大体制改革。因此, 是一种以科研为主导方向的新 型教育体制模式; 而研究性教学则是依存于研究型教育模式同时也是保障新 型高教体制健康运行的有效教学方法。研究型大学䩖须推行研究性教学方法, 但还必须同步进行教学教务管理、学生培养和成绩评定等方面的配套改革, 这些内容与教学方法环环紧扣, 缺省任何一项都不能完成研究型大学建设任 务。

\section{2. 研究性教学模式与传统式教学模式的差异比较}

\subsection{1. 传统教学模式及其存在问题}

传统教学模式, 可看成是教学型大学的教育培养模式。该模式下, 学校 是统一行政性控制管理主体、教师和学生为管控目标, 学生受学校和教师双 重控制下的附属品, 学生、教师、学校、上级教育主管机关等自下而上呈层 层遵从的权利控制体系。也就是说, 传统办学类型具有行政控制特征, 是学 生、教师均没有自主性, 学生培养计划由系和学院决定, 教师按照校院两级 教务规定制定课程教学大纲、教案和讲稿, 学生课上课下严格服从于老师安 排教学内容, 学生成绩由教师一人说了算, 如此等等, 学生没有独立创造、 创新空间和自由。这种教学模式割裂了教师和学生双重的专业知识与创造能 力发挥之间的关系, 教师成为被动的授课机器, 同时还是约束学生创造能力 和创新思维的封闭性工具。其模式可用流程图直观描述如图 1 所示:

图 1 看出, 传统教学模式下, 教师受控于学校规章制度, 其讲什么课、 给哪个专业和哪个层次班级讲课、讲什么和讲哪些内容、怎样考评学生成绩 等, 一切都在学校教务部门规定要求下进行, 其专业创新能力和科研传导功 能根本得不到发挥; 同时, 老师的教学效果要同时接受教学督导、同行和学

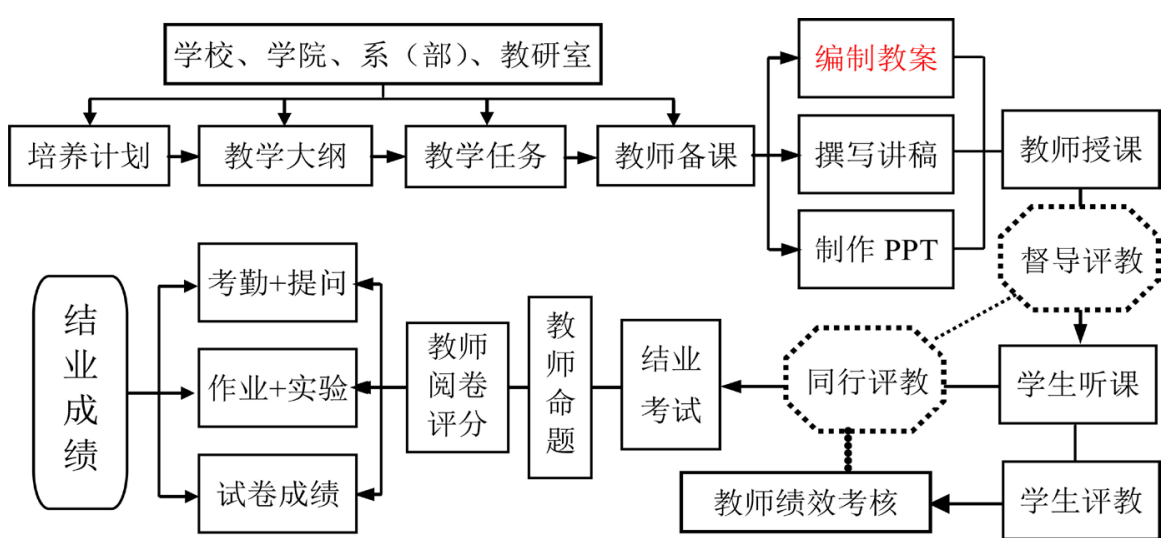

Figure 1. Schematic of traditional teaching training mode

图 1. 传统教学培养模式示意图 
生等 “三级监控” 制约, 并且与其年终 “重点岗位补贴” 和 “讲课费” 等待 遇分配挂钩, 这难免造成教师既要循规蹈矩地遵从 “师风师德”，还要跟同 行、学生协调处理好社会关系, 势必出现部分教师为获得优质评价而过分注 重 “讨好” 学生和同行继而忽略严格控制课堂秩序的不良现象。而学生要顺 利毕业, 既要千方百计处理好同学生管理部门及辅导员的关系, 还要为取得 理想成绩而设法打通教师阅卷和日常考勤等关口。显然, 传统教学模式不仅 抑制创新能力, 还助长了高校官僚作风和教师腐败恶习。

这种模式最大的弊病还直接体现于学生就业矛盾上, 国家教育部和学校 设定的学生培养模式与社会需求存在很大差距, 导致学生毕业难于就业而社 会单位找不到合适人选，出现攻击总量与需求结构的严重冲突; 而教育部和 学校还一味追求就业率。

\subsection{2. 研究型教育背景下的研究性教学模式应用}

研究型大学的最显著特征是学科建设与专业建设并重, 甚至学科建设偏 重于专业建设。在学生培养方案确立环节, 学校规定通识基础课平台, 学院 规定出专业基础课和必修课平台, 素质选修课和专业选修课则只规定出课程 方向、范围和学分, 具体由学生或校内或校外或远程教学平台自主选择研修; 在发展目标上, 以科研和教育教学研究为主导, 强化科研、教研成果管理控 制; 在本科和研究生教学层面, 全面推行研究性教学方法, 课堂教学以学生 为主体, 教师为专业主导, 学校和教师共同服务于学生的集体自主选修专业 课, 远程教学成绩将纳入学分体系, 教师通过案例分析培养学生创造能力、 通过科研学术引导和专题理论剖析启发学生创新思维, 并从理论到实践全面 考核评定学生的专业学分成绩; 在科研学术环节, 教师是科研、教研主体, 应以承担横向、纵向科研课题和开展学术研究为主要工作任务, 同时要将学 生纳入科研学术团队之中, 成为学校科研学术发展的重要辅助力量。如图 2 所示。

图 2 看出, 研究型教育并非对传统办学模式的全盘否定或推倒重来, 而 是保留了原有教学任务部署和教师备课、授课、命题、考试、成绩评定等工 作程序及权利, 但在备课内容上丰富了课堂与学生互动交流和课堂讨论设计

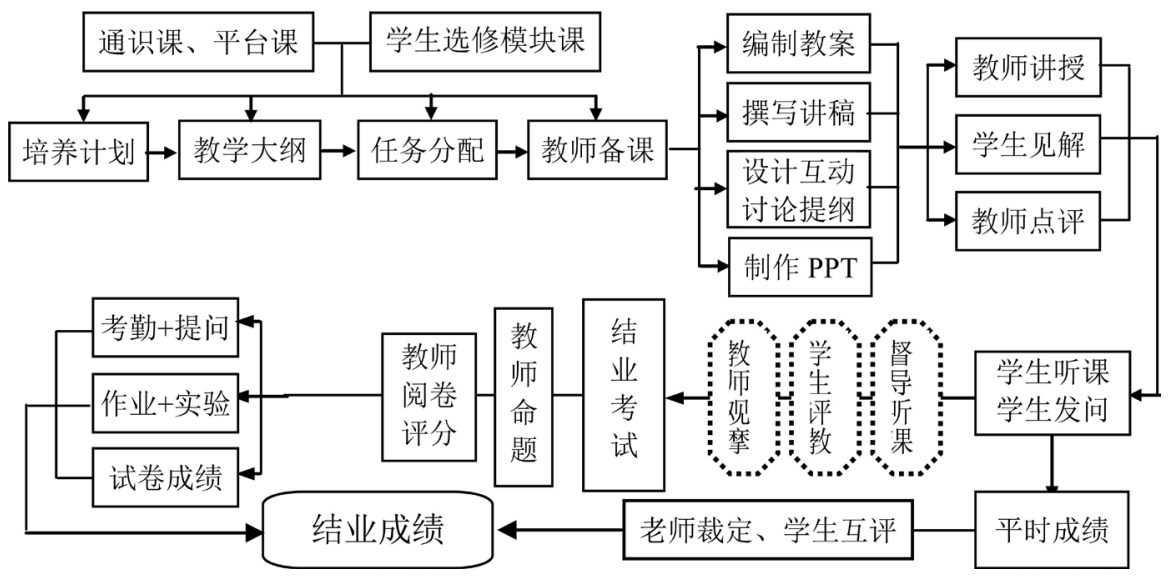

Figure 2. Schematic of research-based teaching training mode

图 2. 研究性教学培养模式示意图 
环节和内容, 并给予学生上讲台发表个人专业见解并接受教师点评机会, 还 由以往单纯的老师讲学生听的教学方式改革为老师讲学生听并就有关疑难或 不同见解向老师发问, 从而大大增强了学生自主学习和与教师主动开展知识 交流、疑点争辩能力, 把讲台变成学生创造能力和创新性思维的培养平台。 此外, 学生平时成绩也由以往教师单方评定, 演变成教师裁量与学生互评相 结合方式, 增强了成绩评定的公开、公平和公正性, 并有效遏制教师利用平 时成绩为个别学生调整个人总成绩的不正之风。

\subsection{3. 研究性教学模式的进步性}

应用型大学的培养定位决定其应该主要采用传统式教育模式, 教学方法 基本是 “填鸭式教学” , 重点教会学生专业或技术的实践应用操作。为此, 教学管理侧重点是学生成绩管理, 强化教师按时按点上下课甚至言谈举止衣 着装扮、学生日常学习出勤、课堂表现、作业及实验记录完成提交等, 都成 为学校纪律性的规章制度约束的重要目标; 课堂教学方式就是老师按部就班 讲课并要求学生认真听课, 学生日常表现成为老师评价其尊重自己教育教学 价值的重要体现。研究型大学的办学定位决定其必须实施研究型教育。为此, 应以研究性教学为主, 课堂教学方式改变较大, 教师除必要的知识性和专业 技术重点难点讲解外, 更多时间交给学生提问或介绍个人认识、理解的看法 和体会, 并且同教师互相讨论、辩论。可见, 传统式教学与研究性教学之间 差异很大, 详见图 3 所示。

比较看出, 与传统教学模式相比, 研究性教学模式具有很多进步性。注 重学生成绩管理并强化对教师和学生的制度约束; 研究型大学则注重科研学 术成果管理, 本科和研究生均吸收为科研学术分子, 共同为学校科研学术成 果效力, 并善于用科学的考评标准来激励和促进教学科研工作。同时, 适应 不同类型大学的教学培养模式差异巨大, 教学型大学仍适宜传统教学模式, 且以 “教授型教学方法” 为主, 专注于学生专业知识和动手操作能力培养; 而研究型大学则仍沿用教授型教学方法但将退居次要地位, 主要教学方法为

“研究性教学”, 因此偏重于对学生综合素质训练和创新研究能力培养。

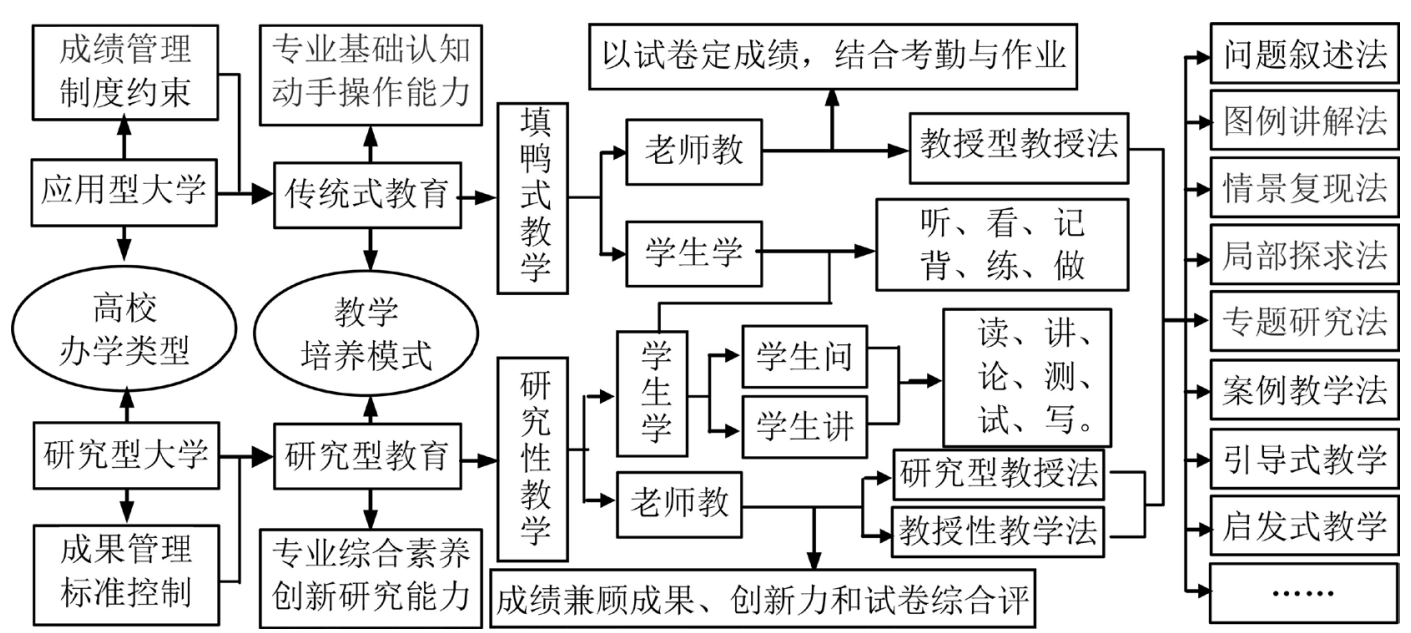

Figure 3. Differentially compare between research-based teaching and traditional teaching

图 3. 研究性教学与传统教学差异比较 
当然, 研究型教育模式并非对教授型教学模式的替代, 而是基于传统教 学模式发展而成, 是对传统教学模式的选择性继承, 是高校办学发展方向转 型和内涵建设提升的必然结果。以往的教学教务组织机构及其课程开发设置、 课程实施纲要和教案或讲义编制、师资队伍建设、课程教学动态信息管理、 课程表编排制定等职能, 特别是教(jiāo)授型教学基本方法统御下的各种具体 教学方法, 包括问题叙述、图解说明、情景复现、局部探求、科学探究、案例 分析、实践调查、引导式、启发式等, 均应全面继承应用[3], 在多媒体运用、沙 盘模拟、手工演示等教学手段上也都一如既往。

\section{4. 高校实施研究型教育模式的指南建议}

研究型教育牵涉到教学管理、教学模式、教学方法等多项应用体制改革 操作, 研究型大学在应用过程中, 需遵循以下几点指南。

\section{1. 激发青年学生的科研学术能量}

高校承担人才培养和科研建设双重任务, 因此高校教师需教学、科研 “双 肩挑”。加之, 科研是国内外评价高校地位的最重要标准, 所以成为高校追 逐的主要建设目标。这也是近年来国内高校纷纷转型建设研究型大学的初衷。 由于教师队伍及其科研力量十分有限, 因此研究型大学建设的重点任务之一, 就是充分挖掘广大青年学生的专业创新潜质, 使之成为高校科研队伍的重要 力量。这样, 不仅可提升学生就业能力, 还能扩大高校科研学术地位和威望。 以在校本科和研究生合计 1.5 万名规模为例, 如果在老师指导下平均有 $50 \%$ 学生发表文章(教师署名通讯作者或第一作者), 每个培养周期(3 4 年)内学校 科研成果就会至少增加 5000 篇论文。这是个惊人的数字, 无疑会强力助推学 校的进步和发展。为此要求做到三点:

1) 实行本科生 “导师制” 培养

导师制是研究生培养普遍采用的教育模式, 应成为建设研究型大学高校 对本科生培养制度, 并作为衡量高校转型成功与否的关键。学生自选导师后, 每个导师组就成为一个相对独立的学习和科研团体, 导师将承担指导学生科 研学术的职责和任务, 不同导师组在专业学习水平、科研学术成果业绩等方 面就会产生竞争, 从而促进学生和导师的科研水平大幅提高。

2) 实行本科专业分方向教学

专业分方向教学, 可以让本科生在个人喜爱的专业范围内实现重点方向 攻关, 提高学生专业实践能力, 增强专业知识的成熟度, 为学生在专业重点 领域内开展深入研究和重点问题的学术性突破奠定基础。本科专业分方向不 宜过多, 既要充分照顾到优质教师资源, 还要认真处理好相关专业方向教学 计划同专业培养计划的相互衔接。

3) 建立激励机制

由于绝大多数期刊杂志发表文章都收取价格不菲的 “版面费”, 学生发 表作品是很大的经济负担。对此, 学校应建立各种激励机制: 一是参照研究 生培养经费办法按导师组人数核拨培养费, 由导师控制专用于学生发表论文, 也可以结合期刊级别和类型规定出报销办法, 学生凭发票报销; 二是制定学 
生科研奖励标准, 奖励额度应不低于论文版面费标准。这样, 就能减轻学生 经济负担, 调动学生发表高水平论文的积极性。

\section{2. 教学管理和督导侧重于教师研究性教学方法应用}

1) 课堂教学须以学生为主体

教学是老师 “教” 和学生 “学” 的双重含义统称。传统教学模式下, 教 师是至高无上权威, 教师是课堂 “主宰者” , 学生只有听、看、记、背、练; 课堂互动也是老师根据自己要求进行提问, 学生应按教师的专业标准回答, 课程结业考试学生需按教师制定 “标准答案” 答题, 否则会影响成绩水平。 虽然传统教学模式强制学生学会很多专业知识和技术本领, 但却严重限制了 大学生的创新性思维和主观能动性发挥。

研究型教育则要求课堂教学以学生为主体, 老师如何教、教什么, 应服 从和服务于大学生学习什么和研究哪些。除专业基础课及专业课的基础性知 识部分外, 教师对专业内容应采用研究性教学方法, 教师在介绍各章节知识 要点和难点后, 就应该将课堂交给学生, 学生可问(疑难点和关注点)、讲(专 业观点和认识)、论(交流讨论)、测(产品、模型和结构等检测)、试(技术性流 程和方法收的试验)、写(专业论文)等, 教师根据学生关注问题进行讲解、引 导、启发和参与讨论, 并指导学生参与科研渠道和撰写发表论文。所以, 研 究型教育真正将学生作为主体, 能够帮助学生自觉控制注意力, 激发其钻研 业务知识积极性, 培养其放散性思维和创新精神。该教学模式下, 教师不再 是教材内容的灌输机器, 也不是教育思维和学习内容的控制者, 而是服务于 学生研究性学习需要的智慧 “充电器” 和专业志趣的方向引路者。

2) 教学管理手段由教师灵活确定

传统教学模式中, 要求教师授课必须带齐 “三件套” : 教学大纲、教案、 讲稿和课件(PPT)。如财会专业教学内容政策依附性强, 教学大纲和内容调整 是常态化工作, 挤占了教师的许多科研和专业攻关的宝贵时间。研究型教育 模式下, 教师应按照学生对相关专业内容需要和研究方向开展教学和辅导。 所以, 课堂教学具体内容和进度均需因事制宜, 僵化的教学大纲、按 “满堂 灌” 设计的教案、按部就班的讲稿等, 都将退出教学管理舞台。代之以新的, 是以教学章节为编制单位的轮廓式大纲, 着重于学生关注点安排教学课件, 针对学生研究关键点灵活设计辅导要点。

3) 教学要求和评价需多样化

传统模式下, 教学主管部门对教学主体一一教师工作职责是备课、上课、 出题、成绩评定等, 教学评价实行教学督导、同行和学生 “三级评教” 。教 师应严格遵循学校规定的教学方案设计、教学组织、教学语言与教态等四方 面考评范围和标准, 终日拖累于循环往复的 “事务性” 工作中, 学校主宰教 师、教师主宰学生, 一切都在制度框架内, 谁也没有自主权。研究型教育模 式下, 学校需要制定出关于教师资质与选择、教师教学责任与权利、专业教 学重点、学生成绩结构与考评、学生专业学习主导权利范围、教学沟通等基 本标准; 同时, 遵循学术竞争规则, 建立新型教研、科研管理办法, 将学生 纳入到学校教研和科研管理系统, 并通过建立学术成果抵学分、指导教师计 
工作量等办法, 调动师生学习和科研竞争的积极性。

4) 教学方法因课制宜

传统教学阶段主要采用教授型教学方法, 具体包括问题叙述、图例讲解、 情景复现、局部探求、专题研究、案例分析等方法。研究型教育模式下, 课 堂教学的基本方法应为研究性教学法, 但绝非研究型大学的所有课程即所有 内容都 “一刀切”, 否则就会出现愚弄学生现象。对本科生而言, 很多内容 属于无专业基础支撑的纯陌生知识，比如基础类课程和专业基础课中的绝大 多数内容, 再有专业课中的基础知识和属于技术性标准(土木工程、力学、化 学等)和规范(美术、乐谱、法规条款)等内容, 教师仍须要采用现行的教授型 方法, 深入浅出地精细讲解传输给学生, 学生通过记忆掌握和应用。对于发 挥性内容、具有创新空间的专业知识, 则适宜采用研究性教学方法, 包括案 例教学、实践教学等具体方法均可广泛应用。

\section{3. 教师管理倾向于自我规范和约束}

传统模式下, 教师凭借一只 “判官红笔” 成为学生们绝对服从的权威, 因此滋生一些有悖师风师德规范和教师腐败问题。教师照本宣科不是个别现 象, 有教材就能上课、教材读得懂就敢接课的现象屡见不鲜; 课堂上学生提 出来的问题, 教师能(愿)答则答, 不能(愿)答就让其自读教材; 在教学内容选 择上, 能将擅讲的事无巨细, 弄不懂的整章节避而不谈。甚至存在课前课后 反复点名, 课上讲故事妄评社会和时政问题等拖延时间现象。研究型教育模 式下, 学生逐步成为教学监督权利主体, 懒惰师风、庸碌师行、腐败师德将 再无容身之所, 面对学生发问必须解答, 学生关注和热衰研究的专业内容教 师必须正确指导和引导, 不能或无法胜任的教师将遭到学生淘汰而退出一线 教学岗位。这必然促进教师自觉加强业务修为和品行操守素养, 严格践行师 风师德标准。学校无需再为教师管理操心, 他们会通过学生选择教师的压力, 强化自我规范和约束。

\section{4. 学生管理应注重创新能力和综合素质}

传统教学模式注重培养学生专业基础认知和动手操作能力, 鼓励学生培 养 “一技之长” ，无形中埋下就业风险，面对现代企业 “一人多岗、一岗多 职、一职多能” 的迫切需求, “一技之需” 的单位和岗位已很鲜见, 就业压 力日益凸显。研究型大学针对新时期社会单位对专业综合素养和创新研究能 力人才需求的新标准, 即不仅能 “上岗就干活” , 还能善于发现问题并主动、 独立地解决问题, 这就是研究型大学才能培养出的 “研究型人才”。所以, 研究性教育培养模式重在通过研究性教学方法实施, 引导大学生自觉培养钻 研专业技术知识、认识社会、判断是非真伪和鉴别虚实优劣的能力, 学会在 简单的职业工作中去创造, 将知识沉积的智慧潜质发挥成现实创造力。

\section{5. 教务管理转向成果管理和标准化控制}

以往的教务管理主要围绕教学计划制定、教学任务下达、教材选订、教 师授课质量、课程考试及成绩登录等相关事务性工作展开, 管理目标即老师 
好好上课学生好好学习。因此, 没人知道也无法考评教师真正的业务水平和 学生的真实能量。教师优劣取决于领导班子, 学生好坏取决于教师印象。多 数高校教师待遇基本同岗同职同酬, 晋职称是专门追求, 为晋职晋岗搞科研 而学术不端成为不争事实; 学生管理最注重学分和纪律两项。只要修满学分 并无重大处分和违规处罚, 毕业 “拿证” 就稳操胜券。因此, “高分低能” 和 “60 分万岁” 的呼声不绝于耳, “代课” 和 “替考” 已是公开秘密。

研究型大学则应注重成果管理和标准控制。教师评价重在教研科研业绩、 “导师制” 培养产生创新成果和专业课研究性教学的满意度等; 学生成绩中 科研学术成果不容忽视, 平时成绩更注重学生向老师发问和同教师争论、向 班级师生汇报讨论成果, 教师提问学生回答的成绩退居次要位置; 学生在课 程结束考试前投稿发表与本课程相关内容的论文表被录用或见刊的, 可免于 结业笔试并应给予优秀档次成绩; 为确保教师评定学生成绩公平, 应按照学 分结构标准实行目标化管理, 学生日常提出多少有价值问题和参与多少专业 演说、讨论、研究, 是否撰写和发表了学术论文, 每项该打多少分或对相关 科目给予免试以及免试成绩底限等, 教师都要现场记录并予以公示, 杜绝课 后随意判定。学习成绩的目标考核标准和公开透明管理, 驱使学生自觉上课 积极性和学习主观能动性, 师生的主从地位逐渐转向平等, 从而消除成绩评 定的不正之风。

\section{5. 结论}

总之, 大学是培养社会需求的高级人才的阵营。高校适宜定位于哪种办 学类型, 首先需围绕自身的教学、科研、师资、试验、就业市场及趋向等各 种综合实力。即, 不能单纯考虑生存发展的需要, 而应更加注重资源条件的 “可能”。所以, 高校运行必须走内涵式发展道路, 其是否转型和如何转型, 同样也是 “内涵式” 跨越。例如, 有些普通大学的综合实力特别是科研学术 地位很差, 充其量也就是区域内的 “知名大学” , 社会认知、认同、认可的 也就是那几十个有限的本科专业, 学生就业去向基本都是很普通的基层企事 业单位, 发展危机四伏, 却将办学类型转为 “教学研究型” 或 “研究教学型” 大学, 甚至放言要建设 “世界一流大学”。这是不尊重国家教育发展标准要 求、无视同类型优秀高校发展和忽视自身客观条件的不负责任决策。所以, 应用型大学决策层在办学类型的转型上, 一定要慎重定位。凡已经确定由教 学型大学转向研究型大学的高校, 都必须努力克服以往以行政为主导而将师 生作为管控目标和对象的落后思想和习惯, 正确地认识到研究型教育是一种 崭新的教育培养模式, 研究型教学则是适应研究型教育培养模式的一种创新 教学方法, 该方法是在传统教学方法基础上发展而来, 客观要求以学生为教 学主体, 以教师为教学主导, 学校相关部门为服务支撑, 科研学术成果创造 为高校工作重心, 并藉此将学生纳入科研队伍和成果管理平台。

\section{基金项目}

黑龙江省教育厅教改工程重点项目 《普通高校财会专业分方向教学与双 导制培养模式研究》(JG2014010913)。 


\section{References}

[1] 王睿. 研究性学习教学模式与策略探析[J]. 中国教育学刊, 2015(s1): 1-2.

[2] 邵光华. 全日制教育硕士专业学位研究生实践教学模式研究[J]. 教师教育研究, 2012(2): 87-91.

[3] 籍建东. 研究型教育模式与传统教学模式的比较 [J]. 职教论坛, 2011(5): 43-45. 